\title{
Microphysical and optical properties of Arctic mixed-phase clouds. The 9 April 2007 case study.
}

\author{
J.-F. Gayet ${ }^{1}$, G. Mioche ${ }^{1}$, A. Dörnbrack ${ }^{2}$, A. Ehrlich ${ }^{3,}$, A. Lampert ${ }^{4}$, and M. Wendisch ${ }^{3, *}$ \\ ${ }^{1}$ Laboratoire de Météorologie Physique, Université Blaise Pascal, Clermont-Ferrand, France \\ ${ }^{2}$ Institute for Atmospheric Physics, DLR Oberpfaffenhofen, Wessling, Germany \\ ${ }^{3}$ Johannes Gutenberg University, Institute for Atmospheric Physics, Mainz, Germany \\ ${ }^{4}$ Alfred Wegener Institute for Polar and Marine Research, Potsdam, Germany \\ *now at: University of Leipzig, Leipzig Institute for Meteorology (LIM), Leipzig, Germany
}

Received: 14 April 2009 - Published in Atmos. Chem. Phys. Discuss.: 6 May 2009

Revised: 3 July 2009 - Accepted: 22 July 2009 - Published: 10 September 2009

\begin{abstract}
Airborne measurements in Arctic boundarylayer stratocumulus were carried out near Spitsbergen on 9 April 2007 during the Arctic Study of Tropospheric Aerosol, Clouds and Radiation (ASTAR) campaign. A unique set of co-located observations is used to describe the cloud properties, including detailed in situ cloud microphysical and radiation measurements along with airborne and co-located spaceborne remote sensing data (CALIPSO lidar and CloudSat radar). CALIPSO profiles indicate cloud top levels at temperature between $-24^{\circ} \mathrm{C}$ and $-21^{\circ} \mathrm{C}$. In situ measurements confirm that the cloud-top lidar attenuated backscatter signal along the aircraft trajectory is linked with the presence of liquid water, a common feature observed in Arctic mixedphase stratocumulus clouds. A low concentration of large ice crystals is also observed up to the cloud top resulting in significant CloudSat radar echoes. Since the ratio of the extinction of liquid water droplets to ice crystals is high, broadband radiative effects near the cloud top are mostly dominated by water droplets. CloudSat observations and in situ measurements reveal high reflectivity factors (up to $15 \mathrm{dBZ}$ ) and precipitation rates $\left(1 \mathrm{~mm} \mathrm{~h}^{-1}\right)$. This feature results from efficient ice growth processes. About $25 \%$ of the theoretically available liquid water is converted into ice water with large precipitating ice crystals. Using an estimate of mean cloud cover, a considerable value of $10^{6} \mathrm{~m}^{3} \mathrm{~h}^{-1}$ of fresh water could be settled over the Greenland sea pool. European Centre for Medium-Range Weather Forecast (ECMWF) operational analyses reproduces the boundary layer height variation along the flight track. However, small-scale features
\end{abstract}

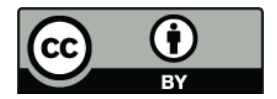

Correspondence to: J.-F. Gayet (gayet@opgc.univ-bpclermont.fr) in the observed cloud field cannot be resolved by ECMWF analysis. Furthermore, ECMWF's diagnostic partitioning of the condensed water into ice and liquid reveals serious shortcomings for Arctic mixed-phased clouds. Too much ice is modelled.

\section{Introduction}

Clouds play a crucial role in the radiative energy budget of the Arctic atmosphere. Sensitive feedback mechanisms include interaction of clouds with the usually high surface albedo in the ice covered Arctic regions, with aerosol, radiation, cloud water content, and cloud drop size (Curry et al., 1996). More especially, the impact of Arctic tropospheric mixed-phase clouds is difficult to predict by current weather and climate models (Inoue et al., 2006). As clouds have a wide variety of physical characteristics, detailed measurements are a key requirement to improve our knowledge of the complex interactions between different physical processes. These measurements may serve as a basis for the development of more accurate microphysical and radiation parameterizations for regional Arctic climate models. Several studies on Arctic clouds have already been published describing microphysical and optical properties during projects such as FIRE-ACE (Shupe et al., 2001), SHEBA (Shupe et al., 2006), and M-PACE (Shupe et al., 2008) and SEARCH (de Boer et al., 2009). For example, extensive in situ observations have been performed in mixed-phase clouds (Hobbs and Rangno, 1998; Lawson et al., 2001; Korolev et al., 2003; McFarquhar and Cober, 2004; McFarquhar et al., 2007) as well as remote sensing observations by Shupe et al. (2001), Intrieri et

Published by Copernicus Publications on behalf of the European Geosciences Union. 
al. (2002), Dong and Mace (2003) and Zuidema et al. (2005). There have also been a number of modeling studies published in the last year through analysis of a couple of case studies of single- and multi-layer mixed-phase clouds during M-PACE (Morrison et al., 2008; Fridlind et al., 2007).

The microphysical properties of Arctic clouds are difficult to retrieve from satellite remote sensing because they are very complex and are often composed of solid and liquid water (mixed-phase clouds). Spherical liquid droplets scatter and absorb/emit atmospheric radiation differently compared to solid ice crystals which are mostly nonspherical. This is one of the reasons why the largest errors in ISCCP (International Satellite Cloud Climatology Project, 2007) cloud climatology occur in the polar region (Rossow et al., 1993). Due to the recent active remote observations from space (Cloud-Aerosol Lidar and Infrared Pathfinder Satellite Observations, CALIPSO, Winker and Trepte, 2007, and CloudSat, Stephens et al., 2002) much more detailed cloud observations are now available. However, serious improvements in satellite retrievals are still hampered, mainly due to the lack of evaluation from dedicated field experiments.

Within this context the Arctic Study of Tropospheric Aerosol, Clouds and Radiation (ASTAR) 2007 project focused on detailed in situ characterisation of microphysical and optical properties of Arctic mixed-phase clouds. The observations allow aerosol-cloud interactions to be studied as well as cloud-radiation interactions and to develop adequate methods to validate cloud parameters retrieved from CALIPSO/CloudSat satellite remote sensing techniques.

This paper focusses on observations obtained from a combination of instruments installed onboard the Polar-2 aircraft operated by the Alfred Wegener Institute for Polar and Marine Research (AWI). These instruments include: a Polar Nephelometer (Gayet et al., 1997), a Cloud Particle Imager (CPI, Lawson et al., 2001) as well as standard Forward Scattering Spectrometer Probe (FSSP-100) to measure cloud particle properties in terms of scattering, morphology and size, and in-cloud partitioning of ice/water content. Remote sensing measurements were obtained onboard the Polar-2 aircraft from the Airborne Mobile Aerosol Lidar (AMALi, Stachlewska et al., 2004) and the Spectral Modular Airborne Radiation measurement sysTem (SMART, Wendisch et al., 2001).

The paper describes in detail the microphysical and optical properties of a mixed-phase boundary-layer cloud observed on 9 April 2007. A unique set of concomitant observations is used for this description, including detailed in situ measurements along with airborne remote sensing observations and co-located spaceborne remote sensing data (Lidar on CALIPSO and radar on CloudSat satellites). Observations are then compared to European Centre for Medium-Range Weather Forecasts (ECMWF) analyses.

\section{Instrumentation, weather situation and flight procedure}

\subsection{Instrumentation}

ASTAR 2007 was carried out from 25 March to 19 April 2007, employing the specially equipped AWI Dornier 228101 aircraft (Polar-2). The research aircraft was instrumented with common instruments for measurements of basic meteorological parameters along the flight track. The instruments used for the determination of microphysical and optical properties of Arctic clouds included three independent techniques: (1) the Polar Nephelometer, (2) the Cloud Particle Imager (CPI) and (3) the PMS FSSP-100 probe. The combination of these techniques provides a description of particles within a diameter range varying from a few micrometers (typically $3 \mu \mathrm{m}$ ) to about $2 \mathrm{~mm}$.

The accuracies of measurements could be hampered by the shattering of ice crystals on probes with shrouded inlet (Polar Nephelometer, CPI and FSSP for instance) (Korolev and Isaac, 2005; Heymsfield, 2007; McFarquhar et al., 2007b). For particle diameters larger than about $100 \mu \mathrm{m}$, the number of shattered particles increases with the concentration of large particles. Techniques have been proposed by Field et al. $(2003,2006)$ to separate real and artifact-shattered crystals from information of ice particle inter-arrival times, making objective corrections possible. New particle image probes with high pixel resolution may also be used to quantify the contribution of shattering to particle size distributions and optical properties (R. P. Lawson, personal communication, 2008). However, these instruments were not available for the present study. The possible effects of ice-crystal shattering on the present study will be discussed together with the results below.

The Polar Nephelometer (Gayet et al., 1997) measures the scattering phase function of an ensemble of cloud particles (i.e., water droplets or ice crystals or a mixture of these particles ranging in size from a few micrometers to about $1 \mathrm{~mm}$ in diameter). Direct measurement of the scattering phase function allows the discrimination of particle shapes (spherical liquid water droplets or nonspherical ice crystals) and the calculation of the integrated optical parameters (such as extinction coefficient and asymmetry parameter, see Gayet et al., 2002). The accuracies of the extinction coefficient and asymmetry parameter derived from the Polar Nephelometer are estimated to be within $25 \%$ and $4 \%$, respectively (Gayet et al., 2002). These measurement uncertainties could be affected by ice-crystal shattering on the probe inlet.

The CPI registers cloud-particle images on a solid-state, one-million pixels digital charge-coupled device (CCD) camera by freezing the motion of the particle using a $40 \mathrm{~ns}$ pulsed, high-power laser diode (Lawson et al., 2001). A particle detection system with upstream lasers defines the focal plane so that at least one particle in the image is in the focus. Each pixel in the CCD camera array has an equivalent size 
in the sample area of $2.3 \mu \mathrm{m}$, so particles of sizes ranging from approximately $10 \mu \mathrm{m}$ to $2 \mathrm{~mm}$ are imaged. The shadow depth of each pixel can be expressed in up to 256 grey levels; the refreshing rate of the CCD camera is $40 \mathrm{~Hz}$. A videoprocessing tool identifies and sizes particles within the pixel array, saving only the regions of interest. The CPI images were processed using the software developed at the Laboratoire de Météorologie Physique (LaMP, Lefèvre, 2007). This software is based on the manual of the original CPIview software (see CPIview, 2005; Lawson et al., 2001; Baker and Lawson, 2006). Moreover, it provides additional information on the ice-particle morphology that is not available from the CPIview software. Our software uses the method proposed by Lawson et al. (2006) for the determination of the ice water content from two-dimensional particle imagery. Without available 2D-C measurements (see Appendix A) the CPI data were used in order to derive particle size distributions and microphysical parameters as Gallagher et al. (2005) in cirrus clouds. The method of calibration of the CPI is described in Appendix A with some results of comparison with 2D$\mathrm{C}$ data obtained during the POLARCAT experiment (Law et al., 2008). The resulting uncertainties on CPI derived microphysical parameters are found of the same order as the 2D-C, i.e. $75 \%, 100 \%$ and $110 \%$ on particle concentration, ice water content and precipitation rate, respectively.

The FSSP-100 instrument was also installed on the Polar-2 aircraft. It provides information on droplet size distribution for the size range of 2-47 $\mu \mathrm{m}$ (Knollenberg, 1981; Baumgardner et al., 2002). The accuracies of the derived extinction coefficient and liquid water content have been estimated as $20 \%$ and $30 \%$, respectively. Referring to the effects of shattering of ice crystals on FSSP data, the bulk parameters could be overestimated by about 15-20\% (Heymsfield, 2007) and the particle concentration by a factor of 2 or 3 (Field et al., 2003). Similar measurement uncertainties due to shattering effects are expected for CPI data.

The Airborne Mobile Aerosol Lidar (AMALi) was operated onboard the Polar-2 aircraft in nadir configuration to probe the backscatter and depolarization properties of the atmosphere below the aircraft. The instrument, its performance and the retrieving technique for the final products are described by Stachlewska $(2004,2006)$ and Lampert et al. (2009). The Polar-2 aircraft was further equipped with the Spectral Modular Airborne Radiation measurement sysTem (SMART, Wendisch et al., 2001) for spectral solar radiation measurements to derive cloud radiative properties (Ehrlich et al., 2008).

\subsection{Meteorological situation}

The observations discussed in this paper were obtained during the Polar-2 flight on 9 April 2007 between 08:30 and 10:50 UTC over the Greenland Sea in the vicinity of the West coast of Svalbard as displayed on Fig. 1. This figure represents the visible image of the Moderate-resolution Imag-

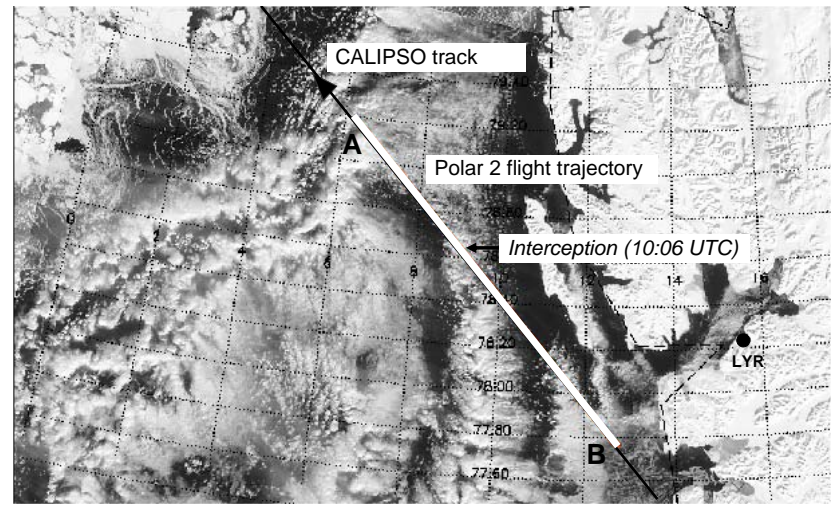

Fig. 1. Satellite picture taken on 9 April 2007 at 10:06 UTC by MODIS (visible channel). The Polar-2 flight trajectory between the way points $\mathrm{A}$ and $\mathrm{B}$ is superimposed to the CALIPSO/CLOUDSAT overpasses. The Polar-2 interception point with the satellite track is indicated. LYR is the location of Longyearbyen.

ing Spectroradiometer (MODIS) satellite at 10:06 UTC and gives an overview of the cloud situation. The weather situation on that day has already been described by Richter et al. (2008). The meteorological data are taken from operational ECMWF analyses. Figure 2 represents geopotential height (in gpdm), equivalent potential temperature and wind speed and direction at $850 \mathrm{hPa}$ level on 9 April 2007 at 12:00 UTC. The approximate location of the airborne observations is indicated by a thick black line.

On the back of a slowly north-eastward propagating trough, cold air was ejected from higher latitudes towards Svalbard. This cold-air outbreak was associated with clouds forming south of the ice edge and extending far south (see Fig. 1). On 9 April 2007, a ridge built up west of Svalbard and disrupted the cold air outflow. After the passage of the ridge axis, warmer and moister tropospheric air from the South replaced the cold air masses from the North.

\subsection{Flight procedure}

On Fig. 1 the along-track of CALIPSO/CloudSat satellites is superimposed with a full black line; the thick white line represents the Polar-2 flight trajectory along which the airborne observations were carried out. The flight path was planned to fit with the satellite along-track with the interception point at 10:06 UTC. During the first part of the flight, simultaneous and co-located measurements with the AMALi lidar and the SMART albedometer (both directed in nadir) were performed. The aircraft altitude was $2700 \mathrm{~m}$; the flight path length was about $250 \mathrm{~km}$ heading straight towards the way point A (see Fig. 1). In the second part of this flight, the aircraft performed a U-turn and descended through the cloud layer. In-situ measurements were carried out during successive descent/ascent slant profiles (between $1700 \mathrm{~m} /-21^{\circ} \mathrm{C}$ and $500 \mathrm{~m} /-12^{\circ}$ ) in order to document the microphysical 


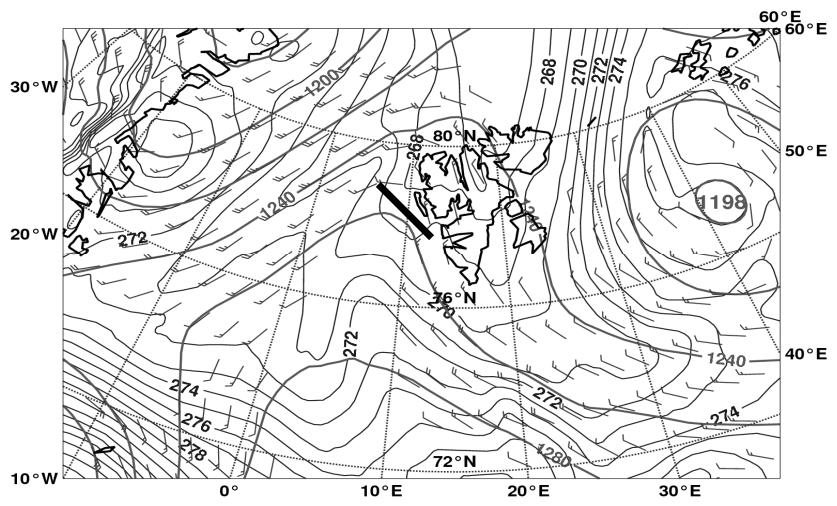

Fig. 2. Geopotential, wind vector and potential temperature fields obtained from the ECMWF analysis at $850 \mathrm{hPa}$ for 12:00 UTC. The black line represents the airborne observation area.

and optical properties of the cloud layer along a horizontal distance of about $250 \mathrm{~km}$, heading towards the way point $\mathrm{B}$ (see Fig. 1).

We note in passing that to reduce inherent errors in comparing quasi-instantaneous spaceborne observations and aircraft measurements carried out during a much longer duration, the flight trajectory was corrected. The method consisted to project the flight path onto the CALIPSO/CloudSat vertical plane by considering the mean wind advection at the corresponding levels and the time difference between satellite and in situ measurements.

In the following section the microphysical and optical properties of the mixed-phase boundary-layer cloud are described and linked with the meteorological situation. The concomitant observations are associated with co-located spaceborne remote sensing data, i.e. CALIOP (CloudAerosol Lidar operated at $532 \mathrm{~nm}$ and $1064 \mathrm{~nm}$ wavelengths with Orthogonal Polarisation at $532 \mathrm{~nm}$ ) on CALIPSO satellite (Winker et al., 2003) and cloud profiling radar operated at $94 \mathrm{GHz}$ on CloudSat satellite (Stephens et al., 2002). The observations are then compared with the ECMWF analyses.

\section{Cloud microstructure}

The vertical structure of the Arctic mixed-phase cloud observed here is first discussed in terms of liquid water phase (supercooled water droplets, see Sect. 3.1) and then in terms of ice water phase (precipitating ice crystals, Sect. 3.2). The liquid water/solid ice phases have been discriminated according to the asymmetry parameter $(g)$, i.e. liquid water droplets have typical values of $g>0.8$ whereas ice crystals have lower g-values (Gayet et al., 2002). In other words and considering visible wavelengths, the first case addresses clouds that can optically be regarded as consisting of liquid water droplets, as the possible occurrence of ice crystals does not significantly affect the optical properties, whereas in the second case the ice-phase is optically dominant with only a weak contribution of possible water droplets on optical properties.

\subsection{Liquid water-phase}

Figure 3a (left panel) displays CALIOP attenuated backscatter profile $(532 \mathrm{~nm}$ channel) at 10:06 UTC along the satellite track represented on Fig. 1 between latitudes $78.55^{\circ} \mathrm{N}$ and $79.25^{\circ} \mathrm{N}$. The superimposed colored lines represent the Polar-2 flight altitude along the trajectory represented on Fig. 1. The aircraft trajectory has been corrected for advection according to the mean wind vector $\left(8 \mathrm{~m} / \mathrm{s}, 250^{\circ}\right)$ in order to reduce inherent errors in comparing quasi-instantaneous spaceborne observations and aircraft measurements carried out during $1 \mathrm{~h}$ approximately. The four panels on Fig. 3a display the vertical profiles of several parameters obtained during the Polar- 2 ascent-descent sequences. They are: the air temperature, the liquid water content (LWC), the extinction coefficient and the cloud effective diameter respectively. These three last parameters were derived from the FSSP-100 data. Without a bulk water probe, the consistency of the FSSP measurements was verified by comparing the extinction coefficient derived with the Polar Nephelometer data. The results show (not presented here) that the slope parameter (0.95) is close to a perfect agreement and the dispersion of the data points $(\sim 20 \%)$ is within the probe uncertainties.

CALIOP measurements indicate a cloud top altitude which varies from $2200 \mathrm{~m}$ to $1700 \mathrm{~m}$. The corresponding temperatures are $-24^{\circ} \mathrm{C}$ and $-21^{\circ} \mathrm{C}$ respectively. The strong backscatter coefficient at the cloud top indicates a liquid water layer and multiple-scattering effects ( $\mathrm{Hu}$ et al., 2007). The cloud layer is optically too thick and attenuates the laser beam significantly, thus reliable lidar measurements are mainly limited to the upper cloud part. However, in a cloud gap at around $79.2^{\circ} \mathrm{N}$, the lidar was able to penetrate to the surface through a cloud layer with a low optical depth thus indicating the occurrence of ice crystals. We notice this feature is confirmed with CALIOP depolarization observations (not shown here) and from remote sensing observations performed onboard Polar- 2 during the first flight sequence above the cloud layer (not shown here). Due to the variation of cloud top altitude the microphysical parameters are plotted with different colors according to the corresponding descent/ascent profiles. At the beginning of the first descent (red part), the liquid water content (LWC) reaches $0.3 \mathrm{~g} / \mathrm{m}^{3}$ at cloud top. During the ascending green profile LWC remains lower than $0.15 \mathrm{~g} / \mathrm{m}^{3}$ whereas LWC increases to $0.23 \mathrm{~g} / \mathrm{m}^{3}$ during the last (blue) ascent. Similar altitude-variations of the extinction are observed with peaks up to $35 \mathrm{~km}^{-1}$ whereas on the average, the effective diameter increases with height from $15 \mu \mathrm{m}$ at $700 \mathrm{~m}$ up to $28 \mu \mathrm{m}$ at $1700 \mathrm{~m}$. No drizzle drops (i.e. droplet diameters larger than $100 \mu \mathrm{m}$ ) were detected in this case from the analysis of the CPI images. Assuming a cloud base at $1200 \mathrm{~m}$, the estimated 


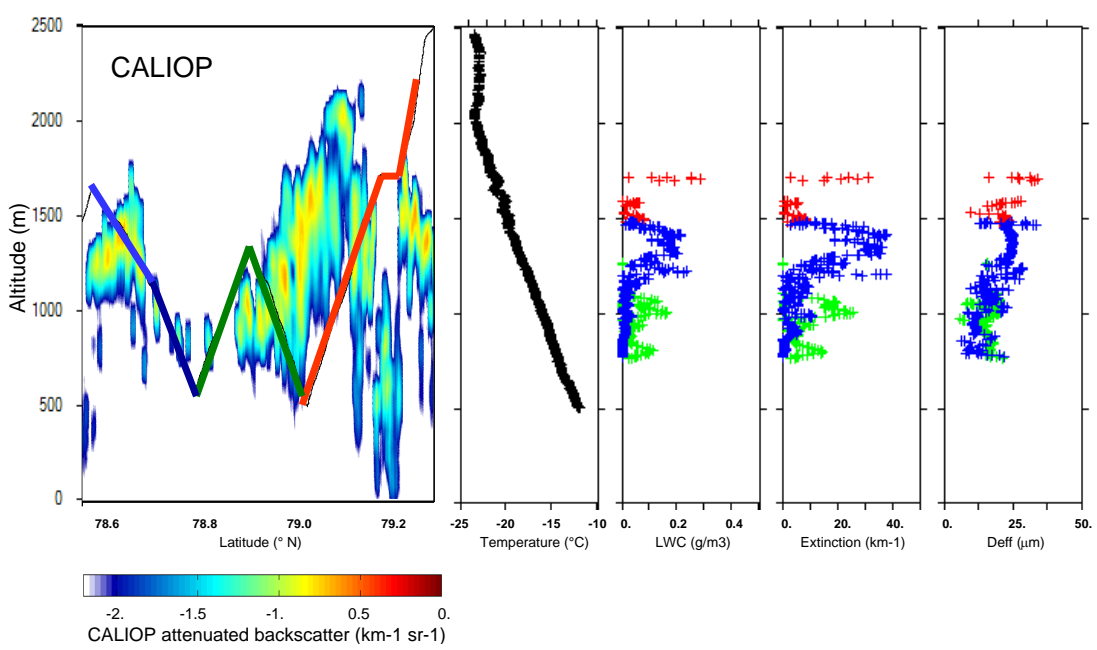

Fig. 3a. CALIOP attenuated backscatter profile (532 nm channel) at 10:06 UT along the satellite track represented on Fig. 1 between latitudes $78.55^{\circ} \mathrm{N}$ and $79.25^{\circ} \mathrm{N}$. In colored line is superimposed the Polar-2 flight altitude. The four panels display the vertical profiles of the following parameters obtained during the Polar-2 ascent-descent sequences: air temperature, liquid water content, extinction coefficient and the effective diameter respectively. The symbols are colored according to the flight sequences.

adiabatic LWC at the highest cloud top level detected by CALIOP $(2200 \mathrm{~m})$ is $0.6 \mathrm{~g} / \mathrm{m}^{3}$, a significantly higher value than the observations. This subadiabatic LWC feature is mainly caused by the fractional cloudiness as evidenced from CALIOP observations and by efficient glaciation processes which deplete liquid water as discussed in Sect. 3.3 below (Bergeron-Findeisen process).

The left panel in Fig. 3b displays the FSSP-100 and CPI particle size distributions (averaged over the flight sequence on Fig. 3a). The upper-right panel represents the average scattering phase function (without normalization in units of $\mu \mathrm{m}^{-1} \mathrm{sr}^{-1}$ ) measured by the Polar Nephelometer (filledcircle symbols) and the theoretical phase function (cross symbols) calculated from the FSSP-100 size distribution assuming (spherical) cloud droplets. The mean values of the parameters (see left panel in Fig. 3b) indicate cloud droplet concentration $\left(40 \mathrm{~cm}^{-3}\right)$, liquid water content $\left(0.06 \mathrm{~g} \mathrm{~m}^{-3}\right)$, extinction coefficient $\left(10 \mathrm{~km}^{-1}\right)$, effective diameter $(18 \mu \mathrm{m})$, asymmetry parameter $(0.838)$ and ice concentration of particle with $D>50 \mu \mathrm{m}\left(1.21^{-1}\right)$. The upper-right panel of Fig. $3 \mathrm{~b}$ shows that the calculated phase function agrees very well at all scattering angles with the observations from the Polar Nephelometer. In other words, the modeled value of the extinction coefficient matches with the measured one. We note in passing the very good consistency of the two independent measurements. This also means that Polar Nephelometer measurements are likely not affected by the presence of ice-crystals detected by the CPI since the liquid water (FSSP-100) to ice crystals (CPI) extinction ratio is about $100\left(10 \mathrm{~km}^{-1} / 0.1 \mathrm{~km}^{-1}\right)$. Subsequently the FSSP-100 cloud droplet measurements do not seem to be significantly contaminated by ice-crystal shattering effects due to a low concentration of ice particles with diameter larger than $100 \mu \mathrm{m}\left(<0.51^{-1}\right)$. Likewise the droplet shattering seems unlikely, due to a low concentration of cloud droplets $\left(\sim 40 \mathrm{~cm}^{-3}\right)$.

\subsection{Ice phase}

Figure 4a (left panel) displays the reflectivity factor of CloudSat radar at 10:06 UTC along the satellite track represented on Fig. 1 between latitudes $78.55^{\circ} \mathrm{N}$ and $79.25^{\circ} \mathrm{N}$. The Polar-2 flight altitude is superimposed to the reflectivity factor with a black line. The four panels on Fig. 4a display the vertical profiles of the following parameters: the concentration of ice particles $(D>100 \mu \mathrm{m})$, the ice water content (IWC), the extinction coefficient and the effective diameter (Deff). As in Fu (1996) and Francis et al. (1994) the effective diameter definition in this study is proportional to the volume/area ratio of ice crystals (Gayet et al., 2004). These parameters were derived from the CPI data. It should be noticed that the in situ parameters reported on Figs. $3 \mathrm{a}$ and $4 \mathrm{a}$ originate from simultaneous measurements carried out along the flight track and are separated on the base of g-values.

CloudSat profile indicates a well defined radar-signal zone (red area) with large values of the reflectivity factor up to $15 \mathrm{dBZ}$. This radar echo is observed beneath the highest liquid water dominated cloud layer detected by CALIOP (see Fig. 3a). A weaker radar echo is detected at about $78.6^{\circ} \mathrm{N}$ latitude whereas scattered echoes are observed between $79.15^{\circ} \mathrm{N}$ and $79.25^{\circ} \mathrm{N}$. Due to surface effects the radar data are not reliable on the first $500 \mathrm{~m}$ above the open sea surface; consequently these data have been removed. According to the flight trajectory most of the in situ observations were 

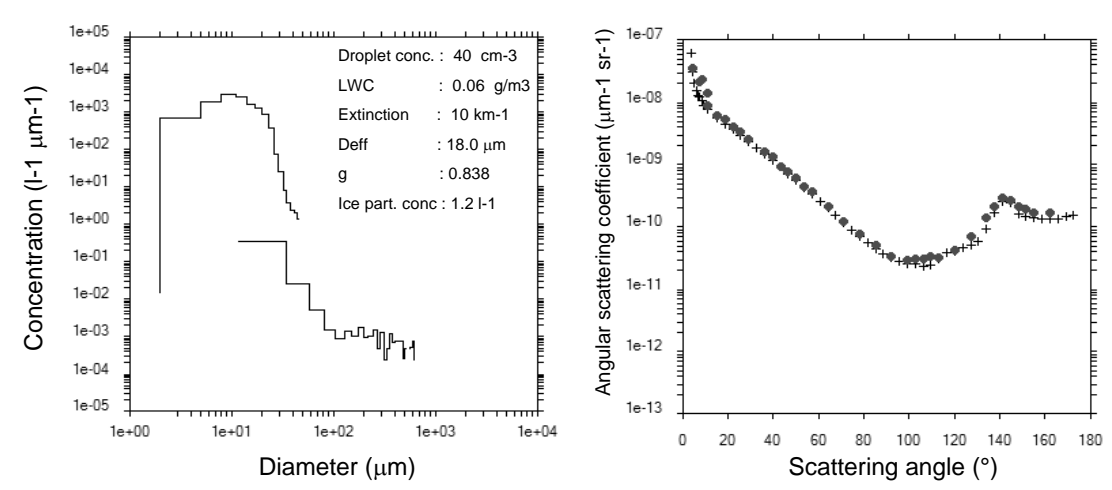

Fig. 3b. Liquid water-phase cloud properties.

Right panel: Mean scattering phase function measured by the Polar Nephelometer (circle symbols) and scattering phase function obtained by Mie theory (cross symbols) calculated with the average droplet size distribution measured by the FSSP-100 over the same time-period. Left panel: FSSP-100 and CPI mean size-distributions. Are also reported the mean values of the pertinent microphysical and optical parameters (Cloud droplet concentration, LWC: liquid water content, extinction coefficient, Deff: effective diameter, $g$ : asymmetry parameter). The concentration of ice particles calculated from the CPI is also indicated.

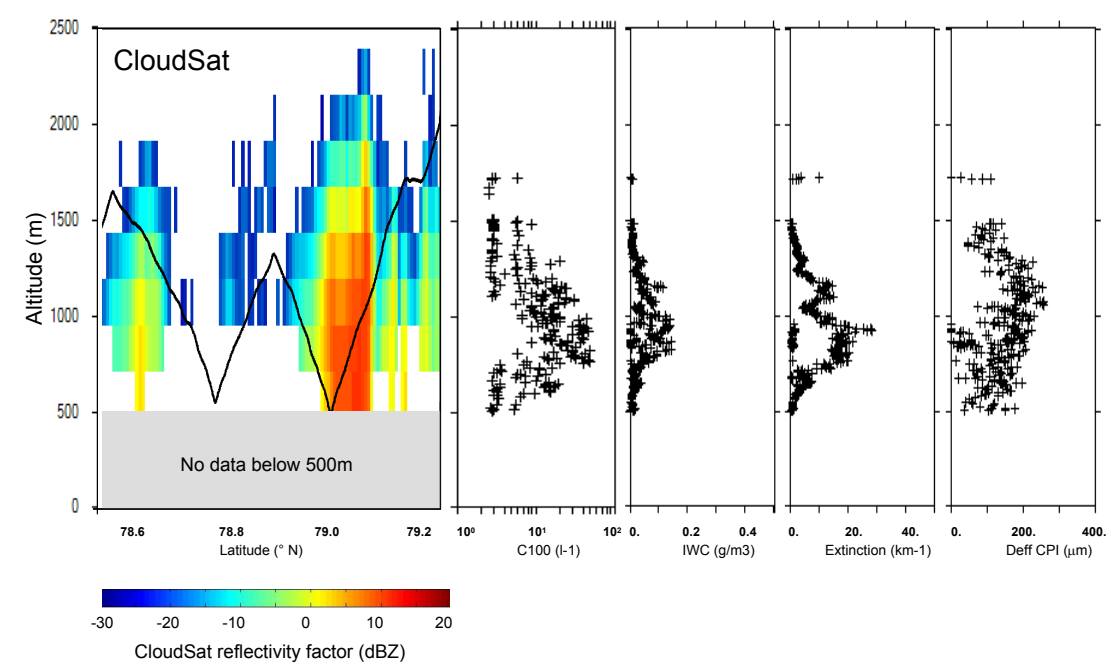

Fig. 4a. CloudSat Reflectivity factor profile at 10:06 UT along the satellite track represented on Fig. 1 between latitudes $78.55^{\circ} \mathrm{N}$ and $79.25^{\circ} \mathrm{N}$. The black line represents the Polar- 2 flight altitude. The four panels display the vertical profiles of the following parameters obtained during the Polar- 2 ascent-descent sequences : concentration ice particles $(D>100 \mu \mathrm{m})$, ice water content, extinction coefficient and the effective diameter of ice particles (all these parameters are calculated from the CPI instrument).

performed during the first descent-sequence through the high radar echo core (see Fig. 4a). The CloudSat signal is correlated with ice precipitation since concomitant in situ measurements reveal the presence of large ice crystals with effective diameter ranging from about $100 \mu \mathrm{m}$ to $200 \mu \mathrm{m}$ and a mean asymmetry factor of 0.778 . This feature has already been observed in Arctic mixed-phase clouds (see among others Shupe et al., 2006). The largest values of ice particle concentration $\left(50 \mathrm{l}^{-1}\right)$, IWC $\left(0.15 \mathrm{~g} / \mathrm{m}^{3}\right)$ and extinction $\left(30 \mathrm{~km}^{-1}\right)$ are observed at an altitude of about $1000 \mathrm{~m}$ when the aircraft reaches the middle of the radar echo core. We recall that the ice particle concentration and extinction could be significantly overestimated by effects of shattering of large ice crystals which are observed in this area (up to $2 \mathrm{~mm}$ ).
It should be noticed that large ice crystals (Deff $\sim 100 \mu \mathrm{m}$, max. size $\sim 800 \mu \mathrm{m}$ ) are observed up to the cloud top but with a lower concentration $\left(\sim 21^{-1}\right)$. This feature explains the observations of radar echoes from CloudSat up to the top of the cloud layer.

The ice particle shape classification (represented by percentage for number concentrations and for $D>100 \mu \mathrm{m}$ ) is depicted on Fig. 5 including some examples of crystal images sampled by the CPI. At the highest in-cloud Polar2 flight level $\left(1700 \mathrm{~m} /-21^{\circ} \mathrm{C}\right)$ the analysis of the particle shapes shows that column, graupels and plates are the dominant shapes (25\% each on the average) as exemplified on Fig. 5a. Side-plane ice crystals $(40 \%)$, plates $(10 \%)$ and graupels $(10 \%)$ are generally observed near $1000 \mathrm{~m} /-16^{\circ} \mathrm{C}$ 
(see examples on Fig. 5b) whereas side-plane and irregular ice crystals are observed near the lowest sampled cloud level $\left(500 \mathrm{~m} /-12^{\circ} \mathrm{C}\right.$, Fig. $\left.5 \mathrm{c}\right)$. Compared to the results from Korolev et al. (1999) who found that only two percent of ice crystals observed in the Arctic are pristine (faceted single crystals) our case study indicates that single columns and plates (i.e. pristine ice crystals) dominate $(\sim 50 \%)$ the particle shape near $-20^{\circ} \mathrm{C}$. Differences in ice particle shape occurrence are also found with regards to the results by McFarquhar et al. (2007) in a similar temperature range from $-12^{\circ} \mathrm{C}$ to $-15^{\circ} \mathrm{C}$. They mostly observed rosette shapes whereas prevalent dendrites $(\sim 40 \%)$ with fewer rosette shape (10\%) characterize our case study.

Figure $4 \mathrm{~b}$ summarizes the microphysical and optical properties of the ice water-phase of the Arctic layer cloud. Assuming that the FSSP probe measures only water droplets, the comparison of the measured phase function and the theoretically calculated one for the assumed pure water cloud shows (see Fig. 4b, right panel) that scattering by ice particles is considerably stronger at all scattering angles, and particularly at side angles between $60^{\circ}$ and $130^{\circ}$, leading to a significantly smaller g-value (0.778) than for the scattering by water clouds. This result confirms the findings by Sassen and Liou (1979) for the mixed-phase clouds formed in their laboratory experiments and those by Gayet et al. (2002) from in situ measurements. Furthermore, the small bump near $145^{\circ}$ on the measured scattering phase function suggests the presence of a relatively small amount of water droplets which still contribute to the scattering properties. This feature may be qualitatively confirmed by the FSSP measurements which evidence a droplet concentration of $2 \mathrm{~cm}^{-3}$ and an effective diameter of $23 \mu \mathrm{m}$. Nevertheless, because of the presence of a relatively large concentration of ice crystals larger than $100 \mu \mathrm{m}\left(51^{-1}\right)$, FSSP-100 and Polar Nephelometer measurements are very likely contaminated by ice crystal shattering, which cannot be quantitatively evaluated without specific instruments such as the Fast-FSSP (Field et al., 2003) and the 2D-S (Lawson et al., 2008). According to the CPI measurements, the mean values of the parameters (see Fig. 4b) indicate concentration of ice particle larger than $100 \mu \mathrm{m}\left(5 \mathrm{l}^{-1}\right)$, ice water content $\left(0.02 \mathrm{~g} \mathrm{~m}^{-3}\right)$, extinction coefficient $\left(0.6 \mathrm{~km}^{-1}\right)$, effective diameter $(70 \mu \mathrm{m}$ from $\mathrm{CPI}$ ) and asymmetry parameter (0.778).

\subsection{Discussion of observations}

Compared to the results from McFarquhar et al. (2007) obtained near Barrow (Alaska) in mixed-phase clouds, the Arctic boundary-layer cloud presented here exhibits a deeper water layer (up to $\sim 1000 \mathrm{~m}$ versus $580 \mathrm{~m}$ ) with higher and colder cloud top $\left(2200 \mathrm{~m} /-24^{\circ} \mathrm{C}\right.$ versus $1150 \mathrm{~m} /-15^{\circ} \mathrm{C}$ on the average). The liquid water cloud has similar microphysical properties with mean droplet concentration and effective diameter of $40 \mathrm{~cm}^{-3}$ and $18 \mu \mathrm{m}$ respectively, whereas a larger ice particle concentration $\left(51^{-1}\right.$ versus $2.81^{-1}$ on average) is evidenced. The liquid fraction defined by $f l=\mathrm{LWC} /(\mathrm{LWC}+\mathrm{IWC}$ ), is subsequently lower (varying between 0.80 and 0.43 from cloud top to cloud base versus $0.97-0.70$ ) and could indicate a less pronounced dominance of the liquid water phase. Nevertheless most of the data with $0.2<f l<0.8$ correspond to the observations carried out through the high echo core (see Fig. 4a) with numerous large ice crystals (up to $501^{-1}$ ). Therefore the FSSP-100 measurements could likely be contaminated by ice crystal shattering leading to overestimated LWC and subsequent fl-values. From previous studies (Cober et al., 2001; Korolev et al., 2003; McFarquhar et al., 2007) mixed-phase clouds typically had $f l<0.2$ or $f l>0.8$ with relatively few values in between, i.e. clouds are dominated either by liquid or by ice.

It is interesting to note that our results are in agreement with those from Garrett et al. (2001) who showed that in Artcic clouds the asymmetry parameter values are decreasing from about 0.86 to 0.75 when the fraction of ice particle number varies from 0 (only supercooled water are present) to 1 (glaciated clouds).

An analysis of the results of Figs. 3 and 4 shows that CALIOP and CloudSat observations can be interpreted in terms of cloud microphysical and optical properties. The observed mixed-phase cloud exhibits a cloud top layer dominated by liquid-water in which ice precipitation was yielded. The visual observation of glory when flying above the cloud layer clearly indicates liquid water cloud droplets. This is a common feature observed in Arctic mixed-phase stratocumulus clouds (Hobbs and Rangno, 1998; Lawson et al., 2001; McFarquhar et al., 2007; Verlinde et al., 2007), which was observed even for cloud top temperatures down to $-25^{\circ} \mathrm{C}$ during ASTAR. A low concentration of large ice crystals is evidenced up to cloud top and leads to significant CloudSat radar echo $(-5 \mathrm{dbZ})$. Since the liquid water (FSSP-100) to ice crystals (CPI) extinction ratio is on average about $100\left(10 \mathrm{~km}^{-1} / 0.1 \mathrm{~km}^{-1}\right)$ the broadband radiative effects near the cloud top are mostly dominated by water droplets as described by Ehrlich et al. (2008) from spectral solar radiation measurements and by Richter et al. (2008) from airborne Lidar observations. These findings confirm the results of McFarquhar et al. (2004) obtained in mixed-phase clouds.

According to investigations of Cho et al. (2008) the relationship between layer-averaged depolarization ratio $(\delta)$ and layer attenuated backscatter $\left(\gamma^{\prime}\right)$ measured by CALIOP gives typical signatures depending on different cloud categories including stratiform clouds in Polar regions. Figure 6 represents the $\delta-\gamma^{\prime}$ relationship obtained from CALIOP measurements discussed in this paper. Our in situ observations confirm that for water clouds consisting of spherical liquid droplets, $\delta$ and $\gamma^{\prime}$ are positively correlated (Hu et al. 2007) and are in agreement with the relationships from Cho et al. (2008) in stratiform polar clouds obtained during one year in latitude belts $60^{\circ}-90^{\circ}$ in both hemispheres. The depolarization ratio increases with the attenuated backscatter due to multiple scattering effects. If most of the scattered data 

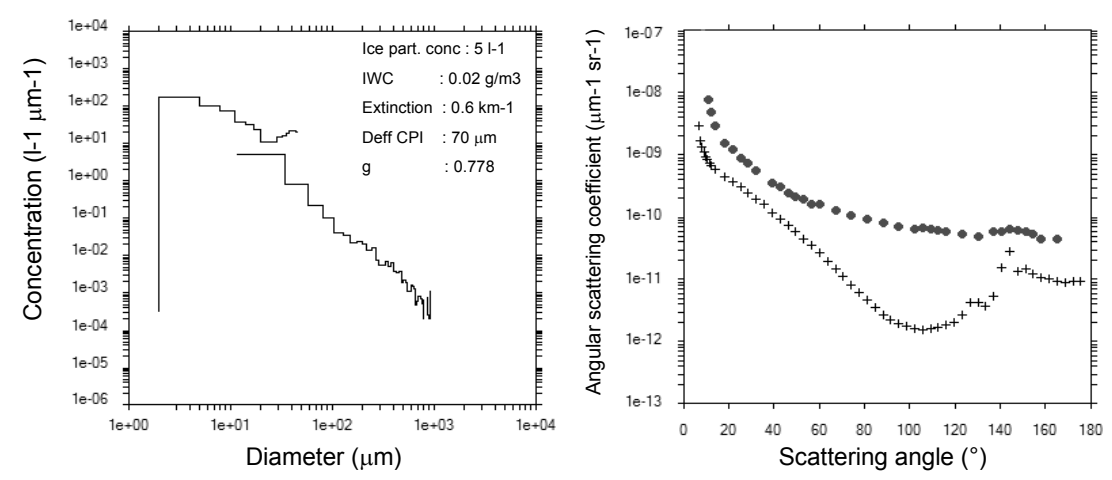

Fig. 4b. Ice water-phase cloud properties.

Right panel: Mean scattering phase function measured by the Polar Nephelometer (circle symbols) and scattering phase function obtained by Mie theory (cross symbols) calculated with the average droplet size distribution measured by the FSSP-100 over the same time-period.

Left panel: FSSP-100 and CPI size-distributions. Are also reported the mean values of the pertinent microphysical and optical parameters (Concentration of ice particles with $D>100 \mu \mathrm{m}$, IWC: ice water content, extinction coefficient, Deff: effective diameter, $g$ : asymmetry parameter).

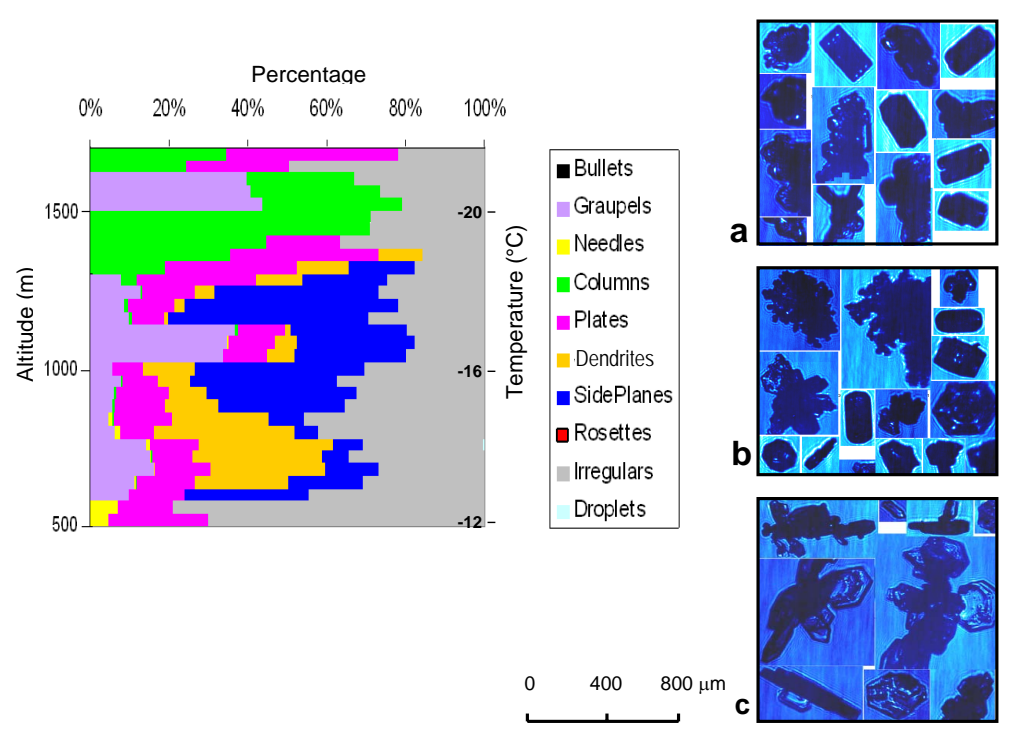

Fig. 5. Vertical profile of the ice particle shape classification (represented for number and for $D>100 \mu \mathrm{m}$ ) with examples of ice particles images sampled by the CPI probe at three flight levels: (a) $1700 \mathrm{~m} /-21^{\circ} \mathrm{C}$, (b) $1000 \mathrm{~m} /-16^{\circ} \mathrm{C}$, (c) $500 \mathrm{~m} /-12^{\circ} \mathrm{C}$.

points on Fig. 6 address water droplets, some measurements with high $\gamma^{\prime}$ and low $\delta$ values are seen as oriented ice crystals according to the theoretical results from $\mathrm{Hu}$ et al. (2007). As already discussed above, they correspond to observations for which the lidar was able to penetrate to the surface and detected precipitating ice particles. The in situ observation of ice columns and plates at the uppermost cloud levels may explain this feature. Nevertheless, because only a few data points are considered the results should be confirmed from new observations performed in Arctic mixed-phase clouds during POLARCAT (Mioche et al., 2009).

In situ measurements as well as CloudSat observations evidence very efficient ice growth processes since about $25 \%$ of the theoretically available liquid water (estimated adiabatic value of $\left.0.6 \mathrm{~g} / \mathrm{m}^{3}\right)$ is converted into ice water $\left(0.15 \mathrm{~g} / \mathrm{m}^{3}\right.$, see Fig. 4a) with large ice crystals with sizes up to $2.1 \mathrm{~mm}$ which precipitate down to the sea level (confirmed by visual observations on board). This feature is highlighted by the relatively strong radar echo core (up to $15 \mathrm{dBZ}$ ) on Fig. $4 \mathrm{a}$. The quantitative comparison of reflectivity factors between CloudSat and in situ observations is displayed on Fig. 7. The method of data processing to derive cloud parameters from in situ data has been described by Mioche et al. (2009) and is discussed in Appendix B. The results highlight a good agreement for the observations carried out around $79^{\circ} \mathrm{N}$ whereas some discrepancies due to likely co-location differences are observed for other echo regions. 


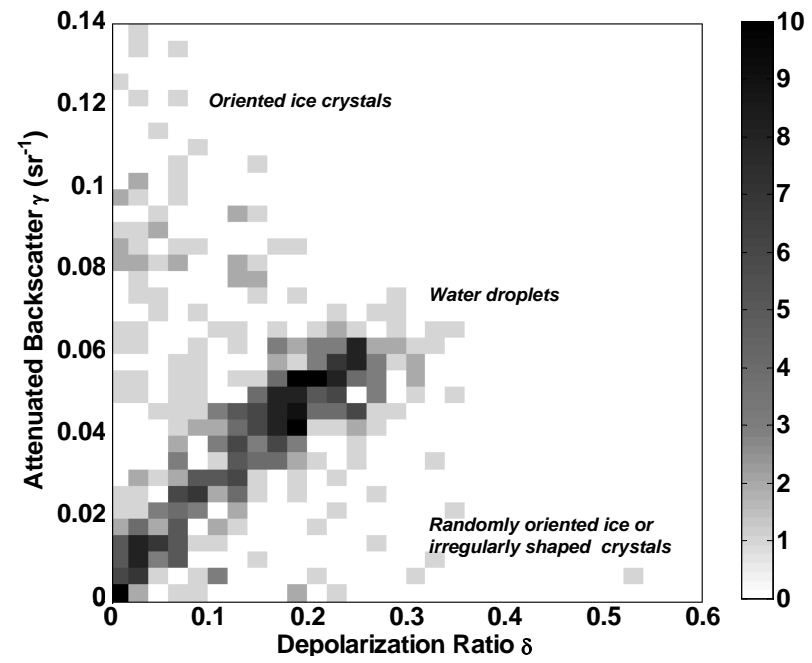

Fig. 6. CALIOP $\delta-\gamma^{\prime}$ relationship obtained for measurements obtained on 9 April 2007. The color of each pixel represents the frequency of occurrence for a $\Delta \delta-\Delta \gamma^{\prime}$ box with 0.02 by $0.004 \mathrm{sr}^{-1}$ interval. The CALIOP horizontal resolution is $333 \mathrm{~m}$.

Boundary layer mixed-phase clouds such as those described in this study in the vicinity of the Svalbard archipelago may cover considerable areas and may last several days. They are generally observed during spring and autumn seasons and are related to cold air outbreaks coming from Northern ice fields (Richter et al., 2008; Kolstad et al., 2008). We have evidenced that such kind of clouds exhibit rather efficient precipitation formation (see also among others McFarquhar et al., 2007). Tziperman and Gildor (2002) have hypothesized that the temperature-precipitation feedback may play an important role in determining the stability of the thermohaline circulation. Therefore, the precipitation rate over the Greenland sea pool is roughly estimated in the following.

The precipitation rate is related to the reflectivity factor as illustrated on Fig. 8 (both parameters are derived from CPI measurements) noting that a reflectivity factor of $15 \mathrm{dBZ}$ corresponds to a precipitation rate of $1 \mathrm{~mm} \mathrm{~h}^{-1}$. Hypothesizing an area of $1000 \mathrm{~km} \times 1000 \mathrm{~km}$ (approximate area of the Greenland sea pool), a precipitation cover of 5\% (rough value from CloudSat data and MODIS cloud field in this study) and a mean precipitation rate of $0.05 \mathrm{~mm} / \mathrm{h}$ (mean value from our in situ measurements), a considerable value of $10^{6} \mathrm{~m}^{3} \mathrm{~h}^{-1}$ of fresh water could be settled over the Greenland sea pool. Obviously this quantity must only be considered as an order of magnitude (i.e. precipitation rate already represents $110 \%$ of error) and should be evaluated much more accurately from interpretation of systematic CloudSat observations and TERRA/MODIS cloud field products over the considered areas.

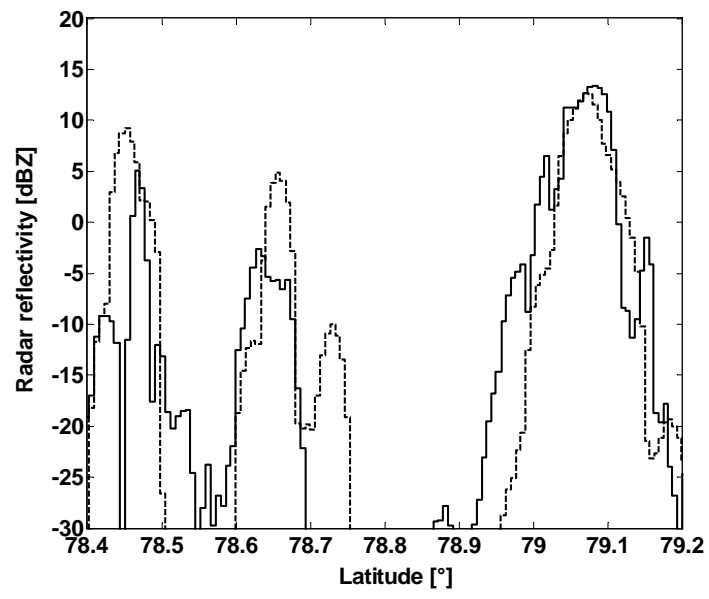

Fig. 7. Time-series of the reflectivity factor derived from CPI measurements (dotted line) and CloudSat reflectivity (full line) along the Polar-2 flight trajectory.

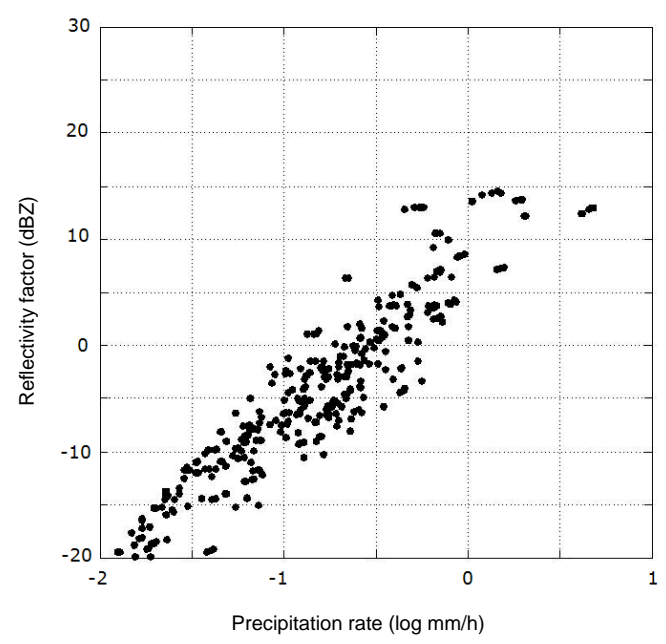

Fig. 8. Relationship between the reflectivity factor and the precipitation rates derived from CPI measurements.

\section{Comparison with ECMWF analyses}

Although numerical prediction models have been improved, clouds represent the largest uncertainty in present weather and climate models. Some of the operational ECMWF analyses are compared with the observations in order to discuss the reliability of microphysical parameterizations which are still a key issue that should be emphasized in numerical modelling of the Arctic atmosphere.

Figure 9 displays CALIOP attenuated backscatter profile along the aircraft trajectory between the latitudes $77.7^{\circ}$ and $79.4^{\circ} \mathrm{N}$. Superimposed are the contour lines of the potential temperature $(\theta)$ and the condensed water content $(C W C=$ LWC + IWC $)$ from ECMWF's operational analyses. Both $\theta$ and CWC fields are spatially and temporally interpolated on the Polar-2 flight track. 


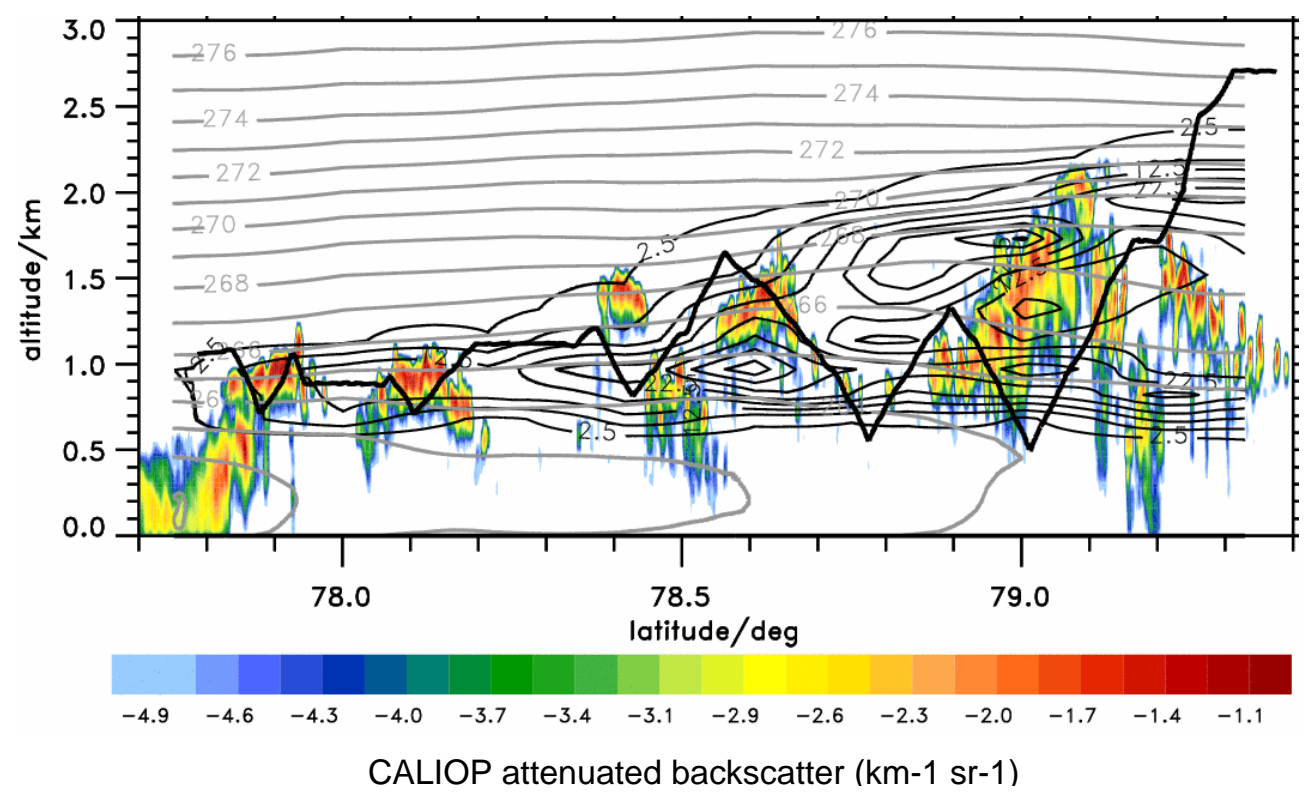

Fig. 9. CALIOP attenuated backscattering profile between the latitudes $77.7^{\circ}$ and $79.4^{\circ} \mathrm{N}$ with the aircraft trajectory. Are superimposed the potential temperature and condensed water content (CWC) contour lines. These two last parameters are issued from interpolated ECMWF operational analyses.

CALIOP attenuated backscatter indicates an almost gradual increase of the cloud top height towards the north. This observation agrees with the superimposed isentropic (constant $\theta$ ) surfaces and the CWC which both indicate an increase of the boundary layer depth. As indicated in Fig. 2, air masses having a different origin have been sampled: During the southern portion of the research flight, remnants of the cold-air outbreak associated with a shallower cloud top height were observed. This air mass was gradually replaced by warmer air originating from the south, which we sampled during the descent-ascent sequences in the northern portion of the flight. A good agreement is found between the structure of the modelled CWC fields and CALIOP observations. Indeed cloud top and cloud base defined by the contour of the threshold modelled CWC value $(0.0025 \mathrm{~g} / \mathrm{kg})$ fit well with the main observed cloud feature. The cloud top level increases from $1100 \mathrm{~m}$ to $2200 \mathrm{~m}$ (towards the Northern part) whereas the coherent cloud base remains at a quasi-constant altitude $(600 \mathrm{~m})$. This implies that the weather situation did not change much between the two analyses times 06:00 and 12:00 UTC. However, due to the coarse spatial horizontal and vertical resolutions of about $20 \mathrm{~km}$ and $200 \mathrm{~m}$ in the boundary layer, the ECMWF analyses cannot resolve the mesoscale features of the observed scattered clouds and therefore does not simulate explicitly shallow convection (it is a hydrostatic model).

These results confirm previous Arctic cloud comparisons with the ECMWF model output during SHEBA (Beesley et al., 2000) where good correlation was found between observations and the vertical extent of clouds.
Now we compare the ECMWF CWC with the in-situ observations point-by-point in a similar way as Sandvik et al. (2007). For this purpose, we interpolate the six hourly ECMWF data to the time, latitude, longitude and altitude of each single airborne measurement point. Figure $10 \mathrm{com}$ pares the modelled (left panel) and measured quantities (right panel): The red and black symbols indicate the liquid water phase (LWC) and the ice water phase (IWC), respectively. Mean values of measured LWC and IWC were calculated over a horizontal distance of about $1500 \mathrm{~m}$. The horizontal bars represent the standard deviations which result from the horizontal cloud variability over this distance. Figure 10 clearly indicates that partitioning between ice and liquid phase in the ECMWF analyses is different compared to the observations. The ECWMF analysis shows that most of the cloud layer consists of ice and only in the lowermost cloud layer (between $600 \mathrm{~m}$ and $1500 \mathrm{~m}$ ) is liquid water found. Thus, the modelled liquid fraction $(f l)$ ranges from 0 to about 0.1 against $0.43-0.8$ as calculated from the observations. However, the measurements show that liquid water dominates the upper part of the cloud. This faulty feature of the ECMWF analysis can be explained by the temperature-dependent diagnostic partitioning scheme between liquid water and ice water phases, as the ECMWF only transport a single variable for the condensed water prognostically. The condensation phase is a diagnostic function of temperature varying from $100 \%$ ice at $250 \mathrm{~K}\left(-23^{\circ} \mathrm{C}\right)$ to $100 \%$ liquid at $273 \mathrm{~K}$. Indeed, for temperature smaller than $253 \mathrm{~K}\left(-20^{\circ} \mathrm{C} / 1500 \mathrm{~m}\right), f l$ is smaller than $2 \%$. Furthermore, the magnitudes of the modelled LWC and IWC values 
on Fig. 10 are much smaller than those observed (by a factor of about 10).

Although the presence of ice is well predicted by the model, despite with significant differences in magnitude compared to the observed values, the properties of the precipitation which fall down to the sea surface due to large ice crystals are not resolved by the model (see black symbols on Fig. 10). Similarly unresolved is the scattered feature of the precipitation fields evidenced from CloudSat (see Fig. 4a). Only more advanced microphysical schemes in cloud-resolving mesoscale models could improve the results but these schemes are not applicable in the context of the ECMWF model. In conclusion the spatial scale plus the microphysical scheme influence the comparison of modelled and observed cloud properties.

These results confirm the conclusions by Beesley et al. (2000) that the ECMWF model did not reproduce the observed fraction of water (due to the temperature-dependent parameterization of water phases) and provided a systematic underestimation of the liquid phase. Morrison and Pinto (2006), Sandvik et al. (2007) and Prenni et al. (2007) also reported on inadequate microphysical schemes underestimating the liquid phase for Arctic mixed-phase clouds.

\section{Conclusions}

The combination of CALIPSO/CloudSat data with colocated in situ observations gives new insights on mixedphase layer clouds in the Arctic region. The results may serve to improve model predictions and satellite retrievals and can be summarized as follow:

The mixed-phased cloud on 9 April 2007 exhibits a cloud top layer dominated by liquid-water in which ice precipitation was yielded. This confirms the common feature observed in Arctic mixed-phase stratocumulus clouds even for cloud top temperatures down to $-25^{\circ} \mathrm{C}$ during ASTAR. A low concentration of large ice crystals is also observed up to cloud top, resulting in significant CloudSat radar echo. Since the liquid water to ice crystals extinction ratio is high the broadband radiative effects near cloud top are mostly dominated by water droplets.

Very efficient ice growth processes are evidenced in boundary layer clouds since about $25 \%$ of the theoretically available liquid water is converted into ice water with large precipitating ice crystals down to sea level. This feature is highlighted by the relatively high CloudSat radar echo core (up to $15 \mathrm{dBZ}$ ). The precipitation rate was related to the reflectivity factor and using a rough estimate of mean cloud cover, a considerable value of $10^{6} \mathrm{~m}^{3} \mathrm{~h}^{-1}$ of fresh water could be settled over the Greenland sea pool during the 9 April 2007 situation.

ECMWF simulations reproduce the boundary layer height variations and a subsequent good agreement is found between the vertical structure of the modelled condensed water

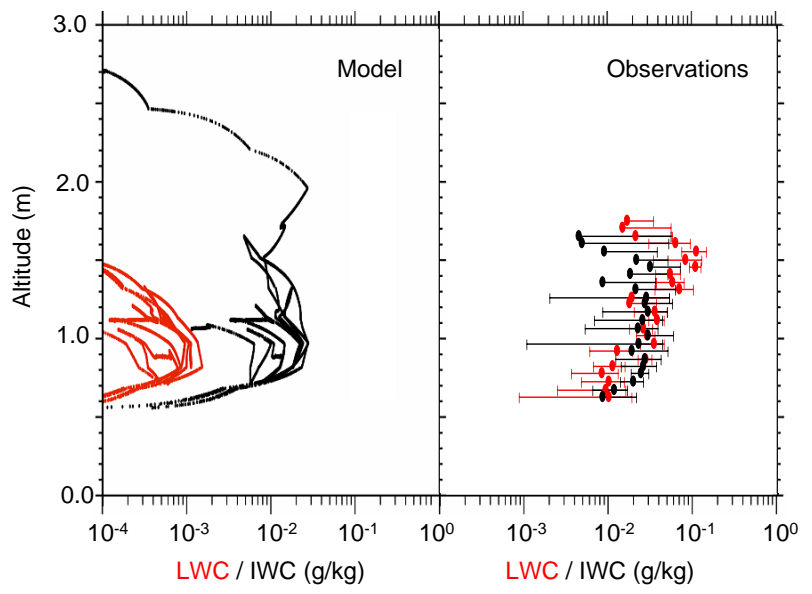

Fig. 10. Vertical profiles of the modelled and observed liquid water content (red symbols). The black symbols represent the modelled and observed ice water content.

content fields and the observations. The modelled cloud top and cloud base fit well with the main observed cloud feature. However, ECMWF analyses cannot resolve the mesoscale features of the observed scattered clouds but rather give a continuous cloudy layer. Comparison with the observations clearly shows that the ECMWF model reveals a serious shortcoming in that most of the cloud layer is classified as ice clouds and only in the lowermost cloud layer is liquid water found. Thus the modelled liquid fraction $(f l)$ is significantly underpredicted because of the temperature-dependent partitioning scheme between liquid water and ice water phases in the model. Furthermore, the magnitudes of the modelled LWC and IWC values are much smaller than observed ones (by a factor of about 10). The properties of the precipitation which falls down to the sea surface as large ice crystals are not resolved (see red symbols on Fig. 10), and neither are the scattered feature of the precipitation fields evidenced from CloudSat. These results confirm previous conclusions that the ECMWF model did not reproduce the observed fraction of water and provided a systematic underestimation of the liquid phase.

\section{Appendix A}

In this paper the cloud microphysical measurements are reported from a PMS FSSP, a Polar Nephelometer and a Cloud Particle Imager. Without available PMS 2D-C measurements the CPI data were used to derive the particle size distributions and the microphysical parameters as Gallagher et al. (2005) in cirrus clouds. Cloud particle sizes, when inferred from images taken with this instrument, are oversized with regards to the true dimension. Furthermore, the subsequent distances on which the particles are accepted in the image frame are 
greater than the depth of field from the object plane. Therefore, large uncertainties occur on derived size distributions particularly for particles smaller than about $100 \mu \mathrm{m}$. In order to reduce these errors, a calibration method was devised (Connolly et al., 2007) from optical bench measurements which use calibrated glass beads and ice analogs. The CPI operated during ASTAR 2004 and ASTAR 2007 campaigns (see Engvall et al., 2008) was calibrated by applying this method at the University of Manchester (Lefèvre, 2007). As reported in a previous paper (Gayet et al., 2009), the calibration results were conclusively validated by comparing the CPI size distributions to the 2D-C data during the ASTAR 2004 campaign. Following a similar way the CPI measurements were compared to PMS 2D-C and 2D-P data still in Arctic layer clouds during the POLARCAT 2008 experiment (Law et al., 2008). We note in passing the ATR42 aircraft used during POLARCAT has very similar performances (in terms of airspeed) of the Polar2 aircraft. Therefore we may reasonably assume that the CPI validations performed from the POLARCAT data are relevant for the results presented in this study. Figure A1a and b displays the results obtained during POLARCAT in a Nimbostratus cloud near $-25^{\circ} \mathrm{C}$ and in a boundary layer mixed-phase cloud near $-15^{\circ} \mathrm{C}$, respectively. A very good agreement is found between the size distributions for both examples with mostly bullet-Rosette ice crystal shape (Fig. A1a) and rimed particles (Fig. A1b). Mean values of the concentration of particles with $D>100 \mu \mathrm{m}$, extinction coefficient and ice water content are also reported on Fig. A1 for CPI probe and both PMS 2D-C and 2D-P instruments. The discrepancies between the two probes are undoubtedly within the large uncertainties expected for the PMS instruments (up to $75 \%$ and $100 \%$ on particle concentration and ice water content respectively, see Gayet et al., 2002) and confirm the previous comparisons results (Gayet et al., 2009). Therefore, we consider the errors on the size distributions and derived microphysical parameters calculated from the (calibrated) CPI are of the same order of those from the PMS instruments.

\section{Appendix B}

The radar equivalent reflectivity factor is calculated by using the following relationshipS (Liu and Illingworth, 2000; Hogan et al., 2005; Protat et al., 2007):

$$
\begin{aligned}
& \left.Z\left(\mathrm{~mm}^{6} \mathrm{~m}^{-3}\right)=10^{15} \frac{\left|K_{i}\right|^{2}}{\left|K_{w}\right|^{2}} \sum_{j, D}\left(\frac{\rho_{e q(j, D)}}{\rho_{g}}\right)^{2} N_{j, D}(D) D^{6} f_{(} D\right) \\
& Z(\mathrm{dBZ})=10 \log _{10} Z\left(\mathrm{~mm}^{6} \mathrm{~m}^{-3}\right)
\end{aligned}
$$

with:

- $K_{i}$ and $K_{w}$ the dielectric factors of ice at $94 \mathrm{GHz}$ (0.177) and water (0.75) respectively;

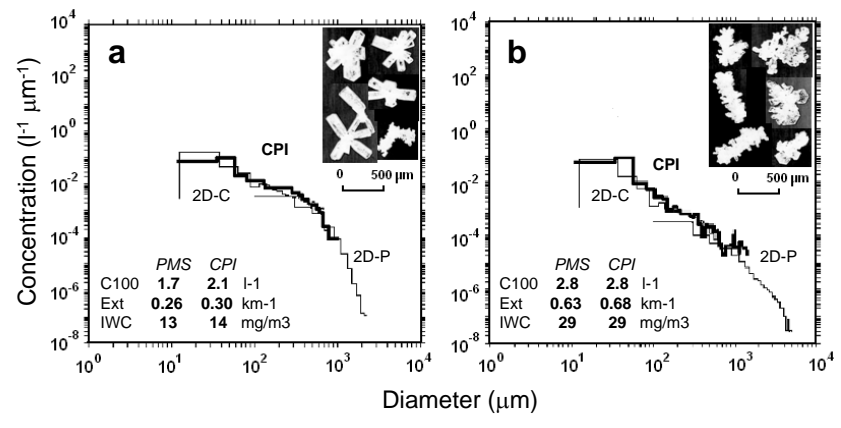

Fig. A1. Mean particle size distributions measured by the 2D-C, 2D-P and the CPI probes obtained during the POLARCAT experiment in a Nimbostratus cloud near $-25^{\circ} \mathrm{C}$ (a) and a boundary layer mixed-phase cloud near $-15^{\circ} \mathrm{C}(\mathbf{b})$, respectively. Mean values of the concentration of particles with $D>100 \mu \mathrm{m}$, extinction coefficient and ice water content are also depicted.

- $\left(\frac{\rho_{e q(j, D)}}{\rho_{g}}\right)$ is the ratio of the equivalent density of ice crystal to the solid ice density in order to take into account the effects of shape and density of ice crystals (Oguchi, 1983). $\rho_{e q}$ is determined according to the shape $(j)$ of the particles recognized from the CPI images (Lefèvre, 2007) and to the corresponding mass-diameter relationships (Locatelli and Hobbs, 1974; Mitchell, 1996). $\rho_{g}=0.9 \mathrm{~g} \mathrm{~cm}^{-3}$;

- $N_{j, D}(D)$ is the concentration of particles $\left(l^{-1}\right)$ with the shape $j$ and diameter $D(\mu \mathrm{m})$;

- $f(D)$ represents the ratio of the Mie scattering to the Rayleigh scattering at $94 \mathrm{GHz}$ which depends on the particle diameter in order to take into account the effects of Mie scattering when the particles are larger than $600 \mu \mathrm{m}$ (see Boudala et al., 2006).

Acknowledgements. This work was funded by the Centre National d'Etudes Spatiales (CNES), by the Institut Polaire Français Paul Emile Victor (IPEV), and the German Research Foundation (DFG, WE 1900/8-1). We thank the members of OPTIMARE $\mathrm{GmbH}$ and DLR (Deutsches Zentrum für Luft- und Raumfahrt) who organize the experiment management and aircraft operations. CALIPSO data presented here are courtesy of the NASA Langley Research Center Atmospheric Science Data Center. CloudSat data are courtesy of the CloudSat Data Processing Center. The ECMWF center is acknowledged for the reliable access to the forecasts and analysis. We acknowledge A. Schwarzenboeck, C. Gourbeyre, G. Febvre and J.-F. Fournol (LaMP) for their active participation to the experiment. We acknowledge K. James who reviewed the manuscript. We thank anonymous reviewers who made important comments which strengthened the manuscript.

Edited by: T. Garrett 


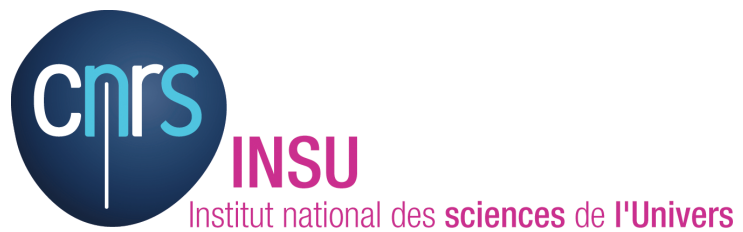

The publication of this article is financed by CNRS-INSU.

\section{References}

Baker, B. and Lawson, R. P.: Improvement in Determination of Ice Water Content from Two-Dimensional Particle Imagery, Part I: Image-to-Mass Relationships, J. Appl. Meteorol. Clim., 45, 1282-1290, 2006.

Baumgardner, D., Gayet, J.-F., Gerber, H., Korolev, A. V., and Twohy, C.: Clouds/Measurement Techniques In Situ, in: Encyclopedia of Atmospheric Sciences, edited by: Holton, J. R., Curry, J. A., and Pyle, J., Academic Press, London, 4000 pp., 2002

Beesley, J. A., Bretherton, C. S., Jakob, C., Andreas, E. L., Intrieri, J. M., and Uttal, T. A.: A comparison of cloud and boundary layer variables in the ECMWF forecast model with observations at Surface Heat Budget of the Arctic Ocean (SHEBA) ice camp, J. Geophys. Res., 105, 12 337-12 349, 2000.

Boudala, F. S., Isaac, G. A., and Hudak, D.: Ice water content and precipitation rate as a function of equivalent radar reflectivity and temperature based on in situ observations, J. Geophys. Res., 111, 1-13, 2006.

Cho, H.-M., Yang, P., Kattawar, G. W., Nasiri, S. L., Hu, Y., Minnis, P., Trepte, C., and Winker, D.: Depolarization ratio and attenuated backscatter for nine cloud types: analyses based on collocated CALIPSO lidar and MODIS measurements, Opt. Express, 16(6), 3931-3948, 2008.

Cober, S. G., Isaac, G. A., Korolev, A., and Strapp, J. W.: Assessing cloud-phase conditions, J. Appl. Meteorol., 40, 1967-1983, 2001.

Connolly, P. J., Flynn, M. J., Ulanowski, Z., Choularton, T. W., Gallagher, M. W., and Bower, K. N.: Calibration of the cloud particle imager probes using calibration beads and ice crystal analogues: The depth of field, J. Atmos. Ocean. Tech., 24, 1860-1879, 2007.

CPIview: CPI data processing software, SPEC Incorporated Boulder, Colorado, (http://www.specinc.com/publications/CPIview_ Manual.pdf), 2005

Curry, J. A., Rossow, W. B., Randall, D., and Schramm, J. L.: Overview of Arctic Cloud and Radiation Characteristics, J. Climate, 9, 1731-1764, 1996.

de Boer, G., Eloranta, E. W., and Shupe, M. D.: Arctic mixed-phase stratiform cloud properties from multiple years of surface-based measurements at two high-latitude locations, J. Atmos. Sci., in press, 2009.

Dickson, B., Yashayaev, I., Meincke, J., Turrell, B., Dye, S., and Holfort, J.: Rapid freshening of the deep North Atlantic Ocean over the past four decades, Nature, 416, 832-837, 2002.

Dong, X. and Mace, G. G.: Arctic stratus cloud properties and radiative forcing derived from ground-based data collected at Barrow, Alaska, J. Climate, 16(3), 445-461, 2003.

Ehrlich, A., Bierwirth, E., Wendisch, M., Gayet, J.-F., Mioche, G., Lampert, A., and Heintzenberg, J.: Cloud phase identification of Arctic boundary-layer clouds from airborne spectral reflection measurements: test of three approaches, Atmos. Chem. Phys., 8, 7493-7505, 2008,

http://www.atmos-chem-phys.net/8/7493/2008/.

Engvall, A.-C., Krejci, R., Str"m, J., Treffeisen, R., Scheele, R., Hermansen, O., and Paatero, J.: Changes in aerosol properties during spring-summer period in the Arctic troposphere, Atmos. Chem. Phys., 8, 445-462, 2008, http://www.atmos-chem-phys.net/8/445/2008/.

Field, P. R., Wood, R., Brown, P. R. A., Kaye, P. H., Hirst, E., Greenaway, R., and Smith, J. A.: Ice particle interarrival times measured with a Fast FSSP, J. Atmos. Sci., 20, 249-261, 2003.

Field, P. R., Heymsfield, A. J., and Bansemer, A.: Shattering and interarrival times measured by optical array probes in ice clouds, J. Atmos. Ocean. Tech., 23, 1357-1371, 2006.

Francis, P. N., Jones, A., Saunders, R. W., Shine, K. P., Slingo, A., and Sun, Z.: An observational and theoretical study of the radiative properties of cirrus: Some results from ICE'89, Q. J. Roy. Meteor. Soc., 120, 809-848, 1994.

Fridlind, A. M., Ackerman, A. S., McFarquhar, G., Zhang, G., Poellot, M. R., DeMott, P. J., Prenni, A. J., and Heymsfield, A. J.: Ice properties of single-layer stratocumulus during the Mixed-Phase Arctic Cloud Experiment, 2. Model results, J. Geophys. Res., 112, D24202, doi:10.1029/2007JD008646, 2007.

$\mathrm{Fu}, \mathrm{Q}$.: An accurate parameterization of the solar radiative properties in cirrus clouds, J. Climate, 9, 2058-2082, 1996.

Gallagher, M. W., Connolly, P. J., Whiteway, J., Figuera-Nieto, D., Flynn, M., Choularton, T. W., Bower, K. N., Cook, C., Busen, R., and Hacker, J.: An overview of the microphysical structure of cirrus clouds observed during EMERALD-1, Q. J. Roy. Meteor. Soc., 131, 1143-1169, 2005.

Garrett, T. J., Hobbs, P. V., and Gerber, H.: Shortwave, singlescattering properties of Arctic ice clouds, J. Geophys. Res., 106, 15 155-15 172, 2001.

Gayet, J. F., Crépel, O., Fournol, J. F., and Oshchepkov, S.: A new airborne polar Nephelometer for the measurements of optical and microphysical cloud properties. Part I: Theoretical design, Ann. Geophys., 15, 451-459, 1997, http://www.ann-geophys.net/15/451/1997/.

Gayet, J.-F., Asano, S., Yamazaki, A., Uchiyama, A., Sinyuk, A., Jourdan, O., and Auriol, F.: Two case studies of winter continental-type water and mixed-phase stratocumuli over the sea 1. Microphysical and optical properties, J. Geophys. Res., 107(D21), 4569, doi:10.1029/2001JD001106, 2002.

Gayet, J.-F., Ovarlez, J., Shcherbakov, V., Ström, J., Schumann, U., Minikin, A., Auriol, F., Petzold, A., and Monier, M.: Cirrus cloud microphysical and optical properties at southern and northern midlatitudes during the INCA experiment, J. Geophys. Res., 109, D20206, doi:10.1029/2004JD004803, 2004.

Gayet, J.-F., Treffeisen, R., Helbig, A., Bareiss, J., Matsuki, A., Herber, A., and Schwarzenboeck, A.: On the onset of the ice phase in boundary-layer Arctic clouds, J. Geophys. Res., in press, 2009.

Heymsfield, A. J.: On measurements of small ice particles in clouds, Geophys. Res. Lett., 34, L23812, doi:10.1029/2007GL030951, 2007.

Hobbs, P. V. and Rangno, A. L.: Microstrusture of low and middlelevel clouds over the Beaufort Sea, Q. J. Roy. Meteor. Soc., 124, 2035-2071, 1998. 
Hogan, R. J., Mittermaier, M. P., and Illingworth, A. J.: The retrieval of ice water content from radar reflectivity factor and temperature and its use in evaluating a mesoscale model, J. Appl. Meteorol., 45, 301-317, 2005.

Hu, Y., Vaughan, M., Liu, Z., Lin, B., Yang, P., Flittner, D., Hunt, B., Kuehn, R., Huang, J., Wu, D., Rodier, S., Powell, K., Trepte, C., and Winker, D.: The depolarization - attenuated backscatter relation: CALIPSO lidar measurements vs. theory, Opt. Express, 15(9), 5327-5332, 2007.

Inoue, J., Liu, J., Pinto, J. O., and Curry, J. A.: Intercomparison of Arctic Regional Climate Models: Modeling Clouds and Radiation for SHEBA in May 1998, J. Climate, 19, 4167-4178, 2006.

Intrieri, J. M., Shupe, M. D., Uttal, T., and McCarty, B. J.: An annual cycle of Arctic cloud characteristics observed by radar and lidar at SHEBA, J. Geophys. Res., 107(C10), 8030, doi:10.1029/2000JC000423, 2002.

IPCC, Intergovernmental Panel on Climate Change: Climate Change 2007 - the Fourth Assessment Report of the IPCC, Cambridge University Press, ISBN 978-0521-88009-1, 2007.

Knollenberg, R. G.: Techniques for probing cloud microstructure, in: Clouds, Their Formation, Optical Properties, and Effects, edited by: Hobbs, P. V. and Deepak, A., Academic Press, New York, 15-91, 1981.

Kolstad, E. W., Bracegirdle, T. J., and Seierstad, I. A.: Marine coldair outbreaks in the North Atlantic: temporal distribution and associations with large-scale atmospheric circulation, Clim. Dynam., 33(2-3), 187-197, 2008.

Korolev, A., Isaac, G. A., and Hallett, J.: Ice particle habits in Arctic clouds, Geophys. Res. Lett., 26, 1299-1302, 1999.

Korolev, A., Isaac, G. A., Cober, S. G., Strapp, J. W., and Hallett, J.: Microphysical charaterisation of mixed-phase clouds, Q. J. Roy. Meteorol. Soc., 129, 39-65, 2003.

Korolev, A. and Isaac, G. A.: Shattering during sampling by OAPs and HVPS. Part I: Snow particles, J. Atmos. Ocean. Tech., 22, 528-543, 2005.

Lampert, A., Ehrlich, A., Dörnbrack, A., Jourdan, O., Gayet, J.F., Mioche, G., Shcherbakov, V., Ritter, C., and Wendisch, M.: Microphysical and radiative characterization of a subvisible midlevel Arctic ice cloud by airborne observations - a case study, Atmos. Chem. Phys., 9, 2647-2661, 2009,

http://www.atmos-chem-phys.net/9/2647/2009/.

Law, K. S., Ancellet, G., Pelon, J., Turquety, S., Clerbaux, C., Pommier, M., de Villiers, R., Gayet, J.-F., Schwarzeboeck, A., Nedelec, P., Schneider, J., and Borrmann, S.: POLARCAT-France Airborne Experiment: first results, Intern. Global Atmospheric Chemistry conference (IGAC), Annecy, France, 7-12 September 2008.

Lawson, R. P., Baker, B. A., and Schmitt, C. G.: An overview of microphysical properties of Arctic clouds observed in May and July 1998 during FIRE ACE, J. Geophys. Res., 106, 14 989-15 014, 2001.

Lawson, R. P. and Baker, B. A.: Improvement in determination of ice water content from two-dimensional particle imagery, Part II: Applications to collected data, J. of Appl. Meteorol., 45(9), 1291-1303, 2006.

Lefèvre, R.: Physique de la mesure de la sonde CPI. Application à la campagne ASTAR, Thèse de l'Université Blaise Pascal. Available at LaMP, 24 av. des Landais 63177 Aubière, France, 187 pp., 2007.
Liu, C. L. and Illingworth, A. J.: Toward more accurate retrievals of ice water content from radar measurements of clouds, J. Appl. Meteorol., 39(7), 1130-1146, 2000.

Locatelli, J. D. and Hobbs, P. V.: Fall speed and masses of solid precipitation particles, J. Geophys. Res., 79, 2185-2197, 1974.

Lubin, D. and Vogelmann, A. M.: A climatologically significant aerosol longwave indirect effect in the Arctic, Nature, 430, 453456, 2006.

McFarquhar, G. and Cober, S. G.: Single-Scattering Properties of Mixed-Phase Arctic Clouds at Solar Wavelengths: Impacts on Radiative Transfer, J. Climate, 17, 3799-3813, 2004.

McFarquhar, G., Zhang, G., Poellot, M. R., Kok, G. L., McCoy, R., Tooman, T., Fridlind, A., and Heymsfield, A.: Ice properties of single-layer stratocumulus during the Mixed-Phase Arctic Cloud Experiment, J. Geophys. Res., 112, D24201, doi:10.1029/2007JD008633, 2007.

Mioche, G., Gayet, J.-F., Minikin, A., Herber, A., and Pelon, J.: A comparison between CloudSat and aircraft data for mixed-phase and cirrus clouds EGU symposium, Vienna, Austria, 19-24 April 2009.

Mitchell, D. L.: Use of Mass and Area Dimensional Power Laws for Determining Precipitation Particle Terminal Velocities, J. Atmos. Sci., 53, 1710-1723, 1996.

Morrison, H. and Pinto, J. O.: Intercomparison of bulk cloud microphysics schemes in mesoscale simulations of springtime Arctic mixed-phase stratiform clouds, Mon. Weather Rev., 134, 18801900, 2006.

Morrison, H., Pinto, J. O., Curry, J. A., and McFarquhar, G.: Sensitivity of modelled Arctic mixed-phase stratocumulus to cloud condensation and ice nuclei over regionally varying surface conditions, J. Geophys. Res., 113, D05203, doi:1029/2007JD008729, 2008.

Oguchi, T.: Electromagnetic wave propagation and scattering in rain and other hydrometeors, Proc. IEEE, 71, 1029-1078, 1983.

Prenni, A. J., Harrington, J. Y., Tjernström, M., DeMott, P. J., Avramov, A., Long, C. N., Kreidenweis, S. M., Olsson, P. Q., and Verlinde, J.: Can ice-nucleating aerosols affect Arctic seasonal climate?, B. Am. Meteorol. Soc., 88, 541-550, 2007.

Protat, A., Delanoë, J., Bouniol, D., Heymsfield, A. J., Bansemer, A., and Brown, P.: Evaluation of ice water content retrievals from cloud radar reflectivity and temperature using a large airborne in situ microphysical database, J. Appl. Meteorol. Clim., 46, 557572, 2007.

Rangno, A. L. and Hobbs, P. V.: Ice particles in stratiform clouds in the Arctic and possible mechanisms for the production of high ice concentration, J. Geophys. Res., 106, 10 065-15 075, 2001.

Richter, A., Gayet, J.-F., Mioche, G., Ehrlich, A., and Dörnbrack, A.: Mixed-Phase Clouds in the Arctic: A Synopsis of Airborne Lidar, In-Situ, and Albedometer Observations, complemented by Meteorological Analyses, 24th International Laser Radar Conference (ILRC), 23-27 June 2008, Boulder, USA, 881-884, 2008.

Rossow, W. B., Walker, A. W., and Garder, L. C.: Comparison of ISCCP cloud detection, J. Climate, 6, 2370-2393, 1993.

Sandvik, A., Biryulina, M., Kvamsto, N. G., Stames, J. J., and Stames, K.: Observed and simulated composition of Atctic clouds: Data properties and model validation, J. Geophys. Res., 112, D05205, doi:10.1029/2006JD007351, 2007. 
Sassen, K. and Liou, K. N.: Scattering of polarized laser light by water droplet, mixed-phase and ice crystal clouds. Part I : Angular scattering pattern, J. Atmos. Sci., 36, 838-851, 1979.

Shupe, M. D., Uttal, T., Matrosov, S., and Frisch, A. S.: Cloud water contents and hydrometeor sizes during the FIRE Arctic Clouds Experiment, J. Geophys. Res., 106, 15 015-15 028, 2001.

Shupe, M. D., Matrosov, S. Y., and Uttal, T.: Arctic mixed-phase cloud properties derive from surface-based sensors at SHEBA, J. Atmos. Sci., 63, 697-711, 2006.

Shupe, M. D., Kollias, P., Persson, P. O., and McFarquhar, G.: Vertical Motions in Arctic Mixed-Phase Stratiform Clouds, J. Atmos. Sci., 65, 1304-1322, 2008.

Stachlewska, I. S., Wehrle, G., Stein, B., and Neuber, R.: Airborne Mobile Aerosol Lidar for measurements of Arctic aerosol, in: Proceeding of the 22nd International Laser Radar Conference, edited by: Pappalardo, G. and Amodeo, A., ESA SP-561, 87-89, 2004.

Stachlewska, I. S.: Investigation of tropospheric arctic aerosol and mixed-phase clouds using airborne lidar technique, Ph.D. thesis, University of Potsdam, 100 pp., http://opus.kobv.de/ubp/ volltexte/2006/698/, 2006.

Stephens, G. L., Vane, D. G., Boain, R. J., Mace, G. G., Sassen, K., Wand, Z. E., Illingworth, A. J., O'Connor, E. J., Rossow, W. B., Durden, S. L., Miller, S., Austin, R. T., Benedetti, A., and Mitrescu, C.: The CloudSat mission and the A-train. A new dimension of space-based observations of clouds and precipitation, B. Am. Meteorol. Soc., 83, 1771-1790, 2002.
Tziperman, E. and Gildor, H.: The stabilization of the thermohaline circulation by the temperature-precipitation feedback, J. Phys. Ocean., 32, 2707-2714, 2002.

Wendisch, M., Müller, D., Schell, D., and Heintzenberg, J.: An airborne spectral albedometer with active horizontal stabilization, J. Atmos. Ocean. Tech., 18, 1856-1866, 2001.

Verlinde, J., Harrington, J. Y., McFarquhar, G. M., et al.: The mixed-phase Arctic cloud experiment (M-PACE), B. Am. Meteorol. Soc., 88(2), 205-221, 2007.

Winker, D. M., Pelon, J., and McCormick, M. P.: The CALIPSO mission: Spaceborne lidar for observation of aerosols and clouds, Status and Performance, Proc. SPIE, 4893, 1-11, 2003.

Winker, D. and Trepte, C.: Distribution and Characteristics of Polar Clouds from CALIOP, A-Train-Lille 07 symposium, 22-25 October 2007.

Zuidema, P., Baker, B., Han, Y., Intrieri, J., Key, J., Lawson, P., Matrosov, S., Shupe, M., Stone R., and Uttal, T.: An Arctic springtime mixed-phase cloudy boundary layer observed during SHEBA, J. Atmos. Sci., 62, 160-176, 2005. 